\title{
Parents' view on the integration of the
} students with special needs in the mainstream education

Nicoleta Lupu 


\title{
Parents' view on the integration of the students with special needs in the mainstream education
}

\author{
Nicoleta Lupu ${ }^{a^{*}}$ \\ a Special School, 125, 13 Decembrie Street, 500164, Brașov, Romania \\ *Corresponding author: gheorghenicoleta22@yahoo.com
}

\section{Abstract}

Keywords: integration, attitude special educational needs
The present article is a qualitative research, aiming to answer the following question: "What is the parents' view regarding the integration of the students with special needs into mainstream schools?" In order to answer this question, the group interview method was employed. The focus group was attended by ten respondents, parents of the typical students of an urban school at the lower secondary school level. The results showed a positive attitude towards people with disabilities in general, but the degree of tolerance and acceptance of the parents decreases when it comes to integrating students with special educational needs with their own children. The data processed through content analysis is a starting point for future research into the community attitudes towards the inclusion of the students with special needs.

\section{Zusammenfasung}

\section{Schlüsselworte:} Integration, Haltung, spezielle pädagogische Bedürfnisse
Der gegenwärtige Artikel ist eine qualitative Forschung, vorhabend, auf die folgende Frage zu antworten: "Was betrachtet die Ansicht von Eltern die Integration der Studenten mit speziellen Bedürfnissen in Hauptströmungsschulen?", um auf diese Frage zu antworten, wurde die Gruppeninterview-Methode beschäftigt(eingesetzt). Die Fokus-Gruppe wurde von zehn Beklagten, Eltern der typischen Studenten einer städtischen Schule am niedrigeren Niveau der höheren Schule aufgewartet. Die Resultate zeigten eine positive Haltung Leuten mit Körperbeschädigungen im allgemeinen, aber dem Grad der Toleranz und Annahme der Eltern-Abnahmen, wenn es zu Integrierung von Studenten mit speziellen pädagogischen Bedürfnissen mit ihren eigenen Kindern kommt. Die Gegebenheiten(Daten) gingen durch Inhaltsanalyse in einer Prozession ist ein Ausgangspunkt für zukünftige Forschung in die Gemeinschaft-Haltungen zur Einbeziehung der Studenten mit speziellen Bedürfnissen.

\section{Introduction}

Enăchescu (1973) considers that the status of the people with disabilities stems from the attitude of society towards disabilities and disabled people. The attitude of the family, the entourage of a deficient child contribute to the formation of a positive or negative self-image. The members of a family having a child with special educational needs can react differently. Năstase (2007) describes the types of reactions, starting from fight, resignation, acceptance to depression, fear, self-blame, denial, anger. And the attitudes of teachers towards the students with special educational needs may range from an attitude of rejection, resistance, fear, indifference to involvement and acceptance. The attitude of the teacher influences those of the disabled student's colleagues and their parents. Lupu (2017) investigated the attitude of a small group of teachers towards the integration of the students with special educational needs in mass education through the group interview method (10 teachers involved in mainstream education, in Braşov county, urban environment, lower secondary school and secondary school level).The results showed a positive attitude. Participating teachers do not believe that disabled students spoil the image of the school, this category of students having the right to education, health and vocational training. Furthermore, participating teachers believe that the students with moderate and severe disabilities can make progress in mainstream school, the presence of a student with special needs in class not being considered extra work for the teacher. Regarding the ranking of disabilities, the teachers find that students with hearing impairment are the hardest to integrate into mainstream education, followed by the severe mental disability and visual impairment. Easier to integrate are the students with physical disabilities and the students with mild mental disabilities.

Regarding the attitude of parents, Palmer et all (1998) apud Palmer et all (2001) shows that parents' for or against 
attitudes depend on their subjective assessment and the context. Pivik, McComas, Laflamme (2002) concluded that the parents of the students believe that the integration of the students with severe disabilities is a difficult process with a negative impact on the other students. Moore (2002) measured the attitude towards integrating of 196 parents of children without disabilities and of 47 parents of children with disabilities. It was also investigated whether parents' attitude differs according to the child's disability. The results showed that parents of both categories of children generally have a positive attitude, the success of integration being dependent on the support and resources of the integrating school. Although there were no significant differences depending on the disability of the child, parents are aware that the integration of the children with severe disabilities will be more difficult. Brandon (2006) shows that the parents of the children with severe disabilities show reluctance and rejection when it is attempted to integrate their children into mainstream education, considering those mainstream classes a place where the teacher is overstrained, overwhelmed and without the necessary experience, where the students are intolerant and without self-control and where the curriculum is inflexible. Yssel et all (2007) shows that parents' perception of inclusion is similar, regardless of the background. Participants in this study were the parents of children with disabilities in two provinces in South Africa and the parents of children with disabilities in two districts in America. The parents participated voluntarily and expressed their view on integration through a focus group. The themes of the focus group were: parental rights, social issues, the acceptance of children with disabilities. The results showed that the political, ethnic, cultural differences between the two continents do not influence parents' expectations, their experiences, frustrations, needs, appreciations. The study highlights the need to train the teachers to work with the parents of children with disabilities. Bochenek (2008) investigates parents' attitudes regarding the integration of children with disabilities into the mainstream education and what they think of the services that an inclusive school offers to these children. The attitude of 271 parents of children with disabilities and parents of children without disabilities from a primary school in Michigan was measured. There were no significant differences between the two groups of parents as regards their attitude towards inclusion. Parents show diverse feelings from worry, reserve to encouraging the integration programs. Hilbert (2009) compares the attitude towards inclusion between the parents of pre-school children with disabilities and the parents of preschool children without disabilities. It has been shown that parents whose children have no disabilities are supportive and permissive in terms of educating their child beside a disabled one. Instead, the parents of the students with special educational needs are reserved regarding the integration into a normal class, anticipating more risks. Their attitude is influenced by the ethnicity and the seriousness of the child's disability.

In Romania, Horga (2009) in a project entitled "The situation of the children with special educational needs included in the mainstream education", developed by the Institute of Educational Sciences, investigated the opinion of the students with and without special needs on this topic, their parents, teachers, school administrators and inspectors through individual interviews, group interviews and a questionnaire. Opinions were asked about the readiness of the educational system to integrate students with special educational needs (human resources, materials), school environment issues (activities for students with special educational needs, group integration, evaluation, collaboration with the family), family environment issues (family perception of school, parent involvement, collaboration with teachers), aspects regarding the wider social environment. The conclusions highlighted the fact that the integration of the students with special educational needs into the mainstream school did not lead to the development of an inclusive school culture. In addition, teachers do not have enough training, they claim difficulties regarding curriculum adaptation, a useless effort considering that The National Evaluation contest does not provide special subjects but only specific organizational conditions. There is criticism of the insufficient number of support teachers, the diagnosis of the student with special needs and monitoring the case. The parents are pleased with the curricular adaptation because the children have the opportunity to solve school tasks. The teachers recall three categories of parents of the students with special educational needs: parents who are actively involved, parents who do not accept the child's listing as having special needs, and parents who have an indifferent attitude. Although the inclusive education policy is not very popular, and there are still schools that do not receive students with special educational needs, the majority of teachers and parents have highlighted the beneficial effects of integration, including the need for socialization. In a sociological study in Chisinau, Malcoci et all (2015) measures the attitude towards inclusion in children with special educational needs and their parents, typical children and their parents, teachers, school managers, and coordinators of centers for inclusive education through 
individual and group interviews. The parents of the typical children consider that any child regardless of health problems can attend school, but the children with physical disabilities are more likely to be accepted in mainstream schools than those with intellectual disabilities and behavioral disorders, arguing that they have inappropriate behaviour that disturbs and the constant need to be supervised. The parents of the students with special educational support the inclusion in mainstream schools, noting that children are thus not isolated, communicating with their fellow students. Instead, the vulnerable families prefer boarding schools.

In a study "The inclusion of the children with disabilities in the education system" in Moldova, 285 boys and 325 girls were interviewed, typical students in lower secondary school and secondary school classes, more than 400 teachers in the primary, lower secondary and secondary school, and over 1300 parents of students with and without special needs. The respondents were asked how the family with a child with special needs should act regarding their education. The vast majority of parents believe that these children should be cared for in the family, others have opted for their placement in special institutions, and only $17 \%$ want them to be enrolled in a mainstream school. For parents, the most rejected group in terms of integration into a mainstream school is the group of mentally disabled students, followed by visual impairment and hearing impairment. To the question "Would you accept children with special needs in the same class with your child?", $38.5 \%$ of the parents answered certainly not, and $34.3 \%$ probably not, with the most rejected being the children with mental disabilities. With regard to the disadvantages of integration, $60.4 \%$ of parents were not able to invoke any disadvantage for the healthy children. The rest have argued that conflicts would arise, that the typical students would be distracted from school classes, and the students with special needs would be offended, discriminated against, and would not cope with the school curriculum. Among the advantages mentioned was socialization, a better subsequent integration into society, the sense of equality, the typical students will become better and more caring.

In a comparative study on knowledge, attitudes and practices in the area of educational inclusion, Cheianu (2011) has come to the following conclusions: parents perceive the student with special needs as a mentally retarded student with hearing or vision difficulties, a child with physical deficiencies attending either a normal school or a special school. Most students, parents, and teachers feel compassion for the students with special needs. Others are against inclusion. 109 teachers, 285 pupils and 285 parents from the Central Region of the Republic of Moldova were interviewed.

The synthesis of the studies presented above allows the following conclusions:

Parents consider that any child, regardless of the health problems has the right to education, but accepting a child with special needs in mainstream schools depends on the type and severity of the deficiency, being more tolerant towards the students with physical disabilities than towards the students with mental deficiencies.

Parents justify that students with special needs through their inappropriate behavior will upset the other students and draw the teacher's attention to them, to the detriment of the other children; in addition, children with special needs will be discriminated against and offended and will not cope with the program and the school curriculum.

Among the advantages of mainstream school integration are: students with special needs socialize, developing the sense of equality, preparing for integration into society, developing the empathy of the typical students

By comparing the attitudes of the parents of the typical students with the attitude of the parents of the students with special needs, it has been shown that the parents of the typical students are more supportive and permissive than the parents of disabled students, who consider the integration of the child with special needs into a normal class as being risky, the success being dependent on the preparation of the inclusive school.

The attitude towards inclusion has been measured through individual and group interviews, questionnaires and Likert Scales.

There is a large number of studies and projects on the inclusion of students with special educational needs in the Republic of Moldova. This area still needs special attention in Romania.

\section{Objectives}

The objective of the study is to investigate the attitude of a small group of parents towards the integration into the mainstream education of students with the special educational needs, as knowing this attitude allows the development of programs aiming at changing attitude and implicitly of favouring integration. 


\section{Materials and methods}

This study is a qualitative research. The method used for data collection is the group interview method. The interview discusses integrating the students with special educational needs into mainstream education and contains 19 questions (opening questions, key questions, final questions). The group interview took place in an integrative school, in Braşov County, with the approval of the headmaster. The Interview Guide is presented in Appendix 1.

Data interpretation is done by analyzing the frequency and prevalence of the answers. The answers provided by parents during the interview were classified and coded on a scale of 1 to 5 in order to be statistically processed, where 1 implies total disagreement, 2-partial disagreement, 3neutral, 4-partial agreement, 5-total agreement.

The participants in the interview are 10 parents of typical students in mainstream education, urban environment, lower secondary level. The participants are aged between 29 and 60 (Figure no. 1), 5 are women, 5 are men, 5 have higher education, 3 high school and 2 secondary education (Figure no. 2). The respondents are not parents of children with special needs, the children of 5 of them are colleagues with the students with disabilities.

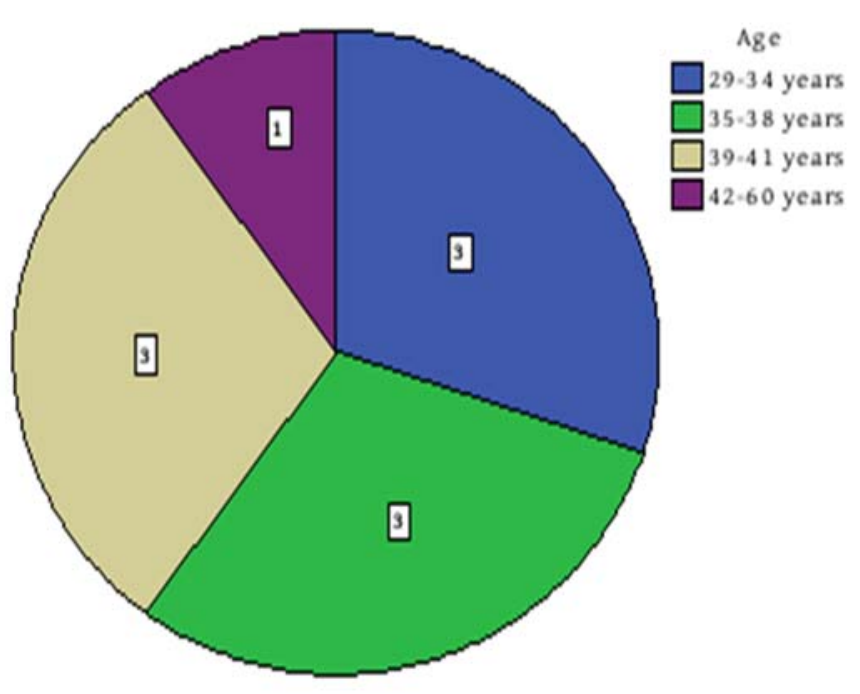

Figure no. 1. The distribution of participants by age

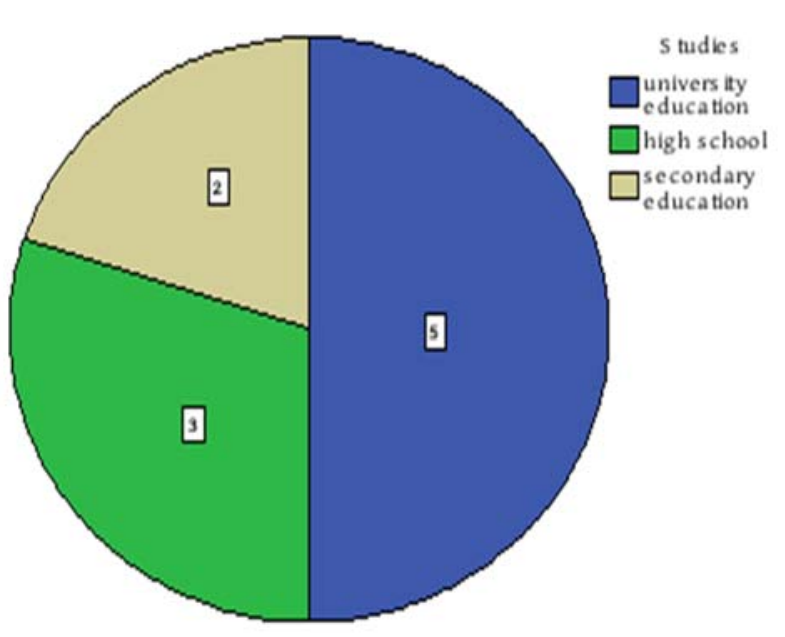

Figure no. 2. The distribution of participants according to their studies

\section{Results}

The parents' answers to the questions in the interview will be presented in the form of graphs.

The questions start from general to particular and investigate the parents' attitudes towards the people with disabilities in general and the attitudes towards the students with special educational needs and their integration with their own children.

Regarding the questions on the integration of people with disabilities in general (Are the people with special needs entitled to health and recovery services?/ Do the people with special needs have the right to education?/ Do the people with special needs have the right to professional training for employment?), all parents have expressed their full agreement with the rights of this category to health, education and professional training.

In the statement "The place of the students with special educational needs is in special education institutions", 6 parents expressed their total and partial disagreement, considering that the place of students with special educational needs is with the other children in the mainstream school, 3 parents agree that students with special educational need to be educated in special schools and one parent remained neutral (Figure no. 3). 


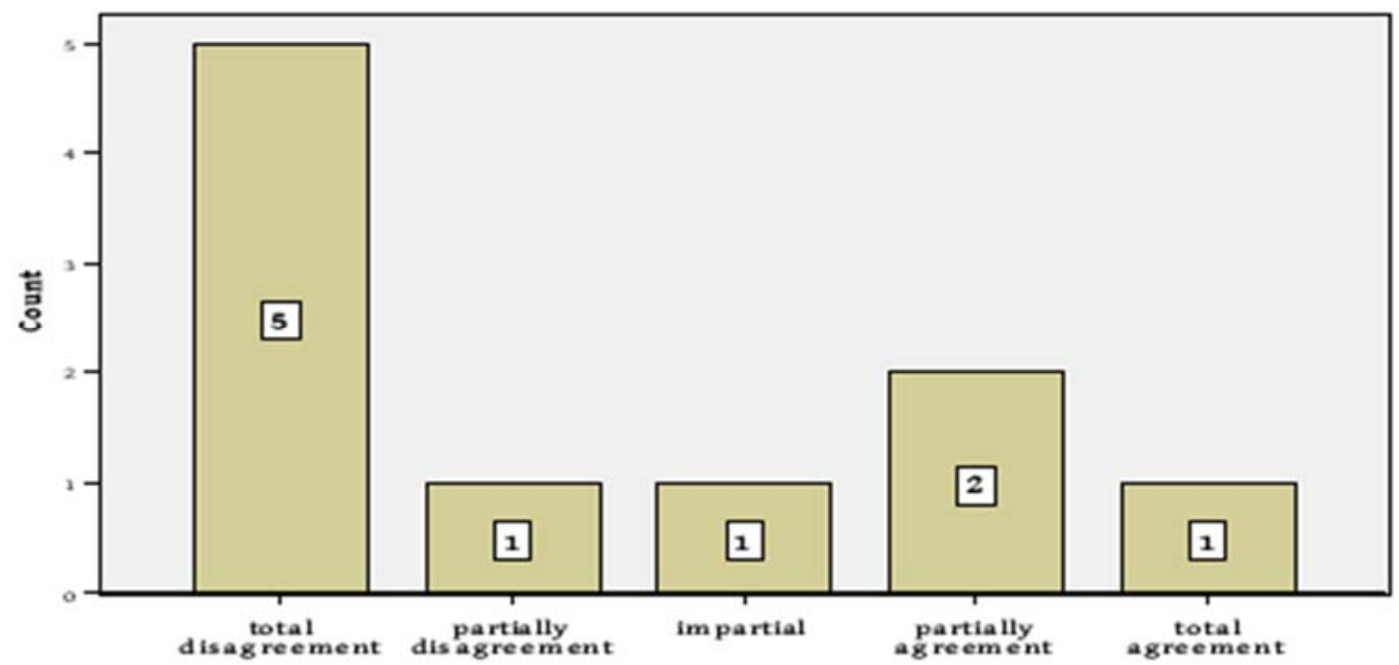

Figure no. 3. Frequency of the answers to the statement "The place of the students with special educational needs is in special education"

In the statement "The place of the students with special educational needs is in special education institutions", 6 parents expressed their total and partial disagreement, considering that the place of students with special educational needs is with the other children in the mainstream school, 3 parents agree that students with special educational need to be educated in special schools and one parent remained neutral (Figure no. 3).

As far as the image of the school is concerned, the parents' opinions are equally divided, 4 parents consider that the students with special educational needs do not spoil the image of the school, while 4 of them think that the image of the school is affected (Figure no. 4).

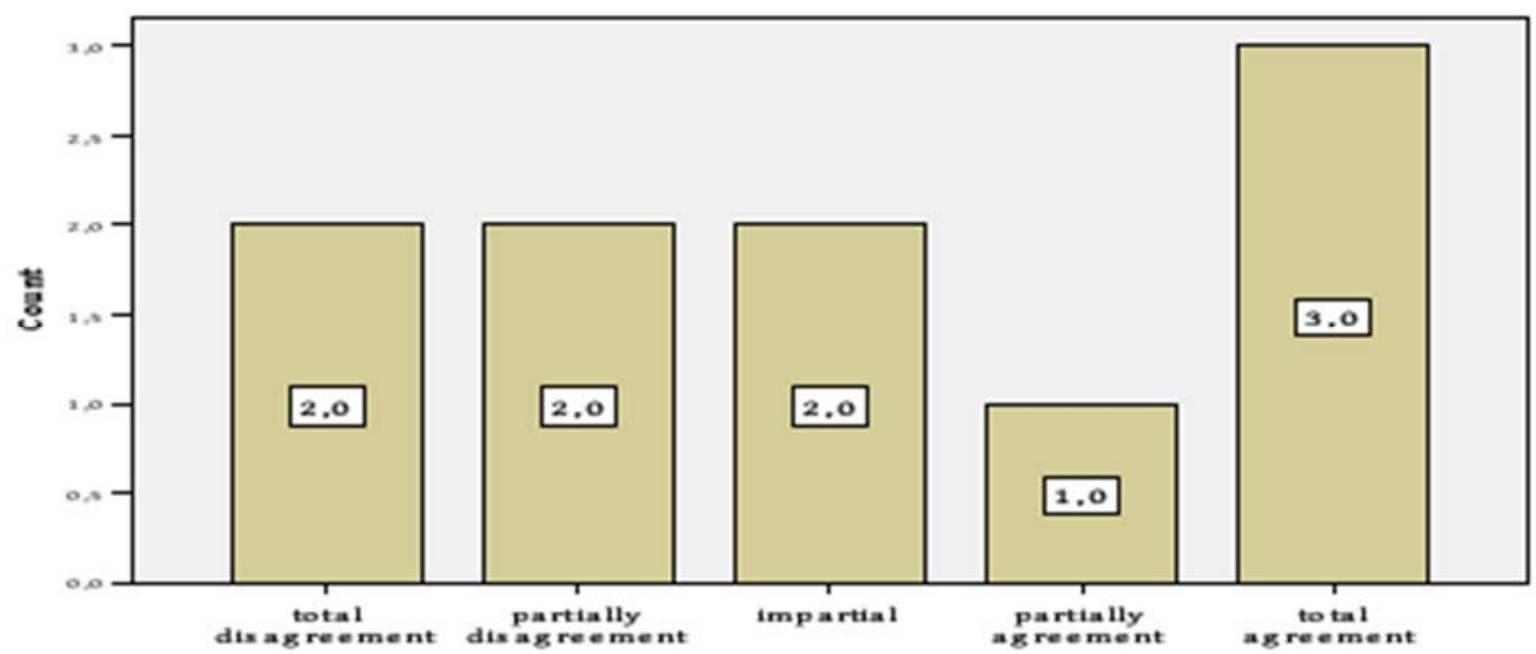

Figure no. 4. Frequency of the answers to the statement "The school image is not affected by the presence of the students with special educational needs"

With regard to the statement "School should not be equipped for the needs of the students with special educational needs because it is not a special school", 6 parents totally and partially agree that a school cannot have the facilities of a special school because it does not address this category (Figure no. 5). 


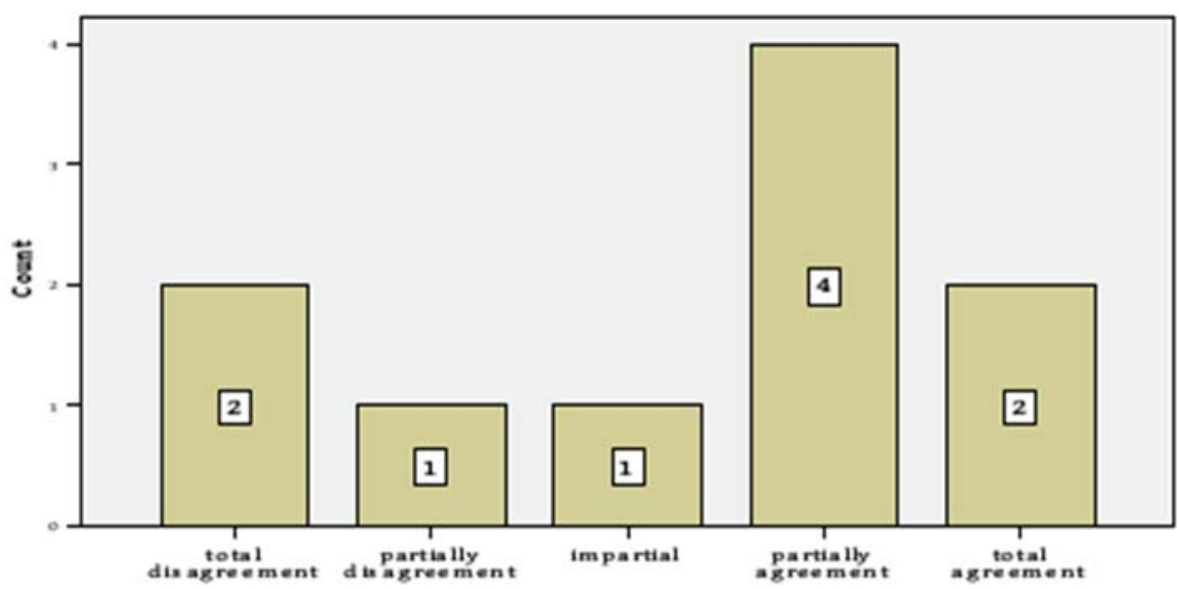

Figure no. 5. Frequency of the answers to the statement "School should not be equipped for the needs of the students with special educational needs because it is not a special school"

The answers to the question "Should school choose the students with special educational needs depending on the severity of their disability?" have highlighted the fact that parents agree to integrate students with special educational needs into mainstream schools but depending on the severity of the disability. Thus, 9 of the respondents stated that only mildly disabled students should be integrated into the mainstream school (Figure no. 6), 7 of them considering that the students with severe disabilities should only be partially integrated, for social development (Figure no. 7).

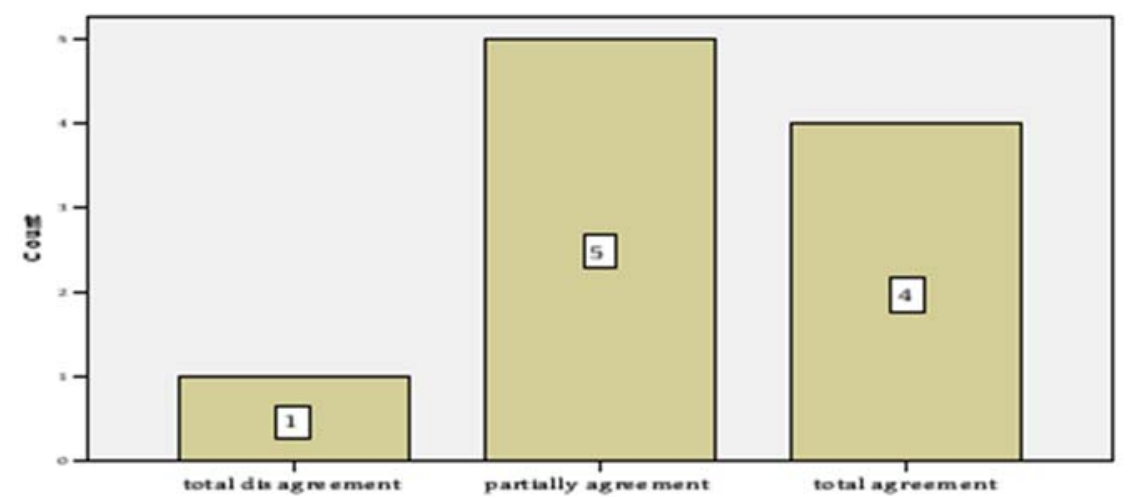

Figure no. 6. Frequency of answers to the statement "Only students with mild disabilities should be integrated into the mainstream school"

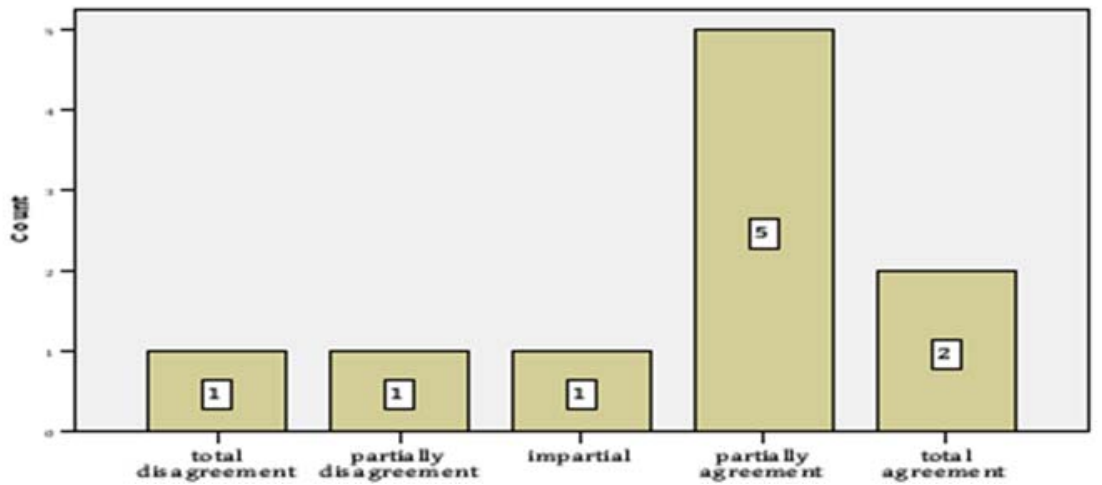

Figure no. 7. Frequency of the answers to the statement "Seriously disabled students should be partially integrated into mainstream schools" 
The answers to the question "Does the presence of the students with special educational needs hinder the classroom activity of other students?" have shown that 6 parents consider that a student with special educational needs can have a negative impact on the typical students (Figure no. 8), attracting the teacher's attention constantly to the detriment of their own children.

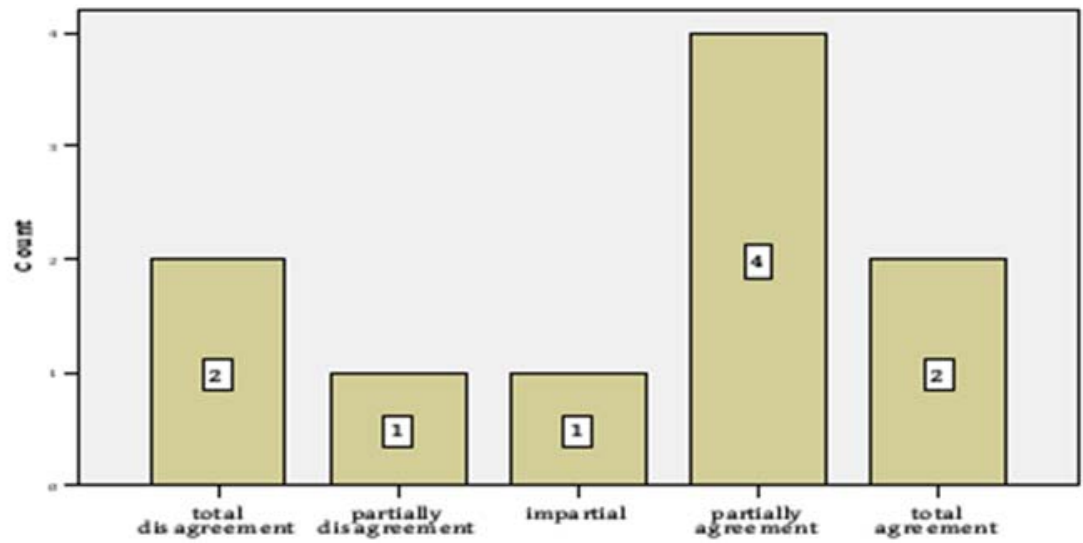

Figure no. 8. Frequency of answers to the statement "The student with special educational needs has a negative impact on the other students in a class"

As a result of the questions regarding the integration of the students according to the type of disability, the following ranking can be seen. At the top of the pyramid, there is the type of disability that is difficult to integrate, and at the base of the pyramid there is the type of slight disability easy to integrate in the mainstream school (Figure no. 9). It can be noticed that the students with physical disabilities and language deficiencies are more easily accepted into mainstream schools compared to the students with severe mental disabilities and students with sensory impairments, the parents being of the opinion that teachers are not prepared to work with such students.

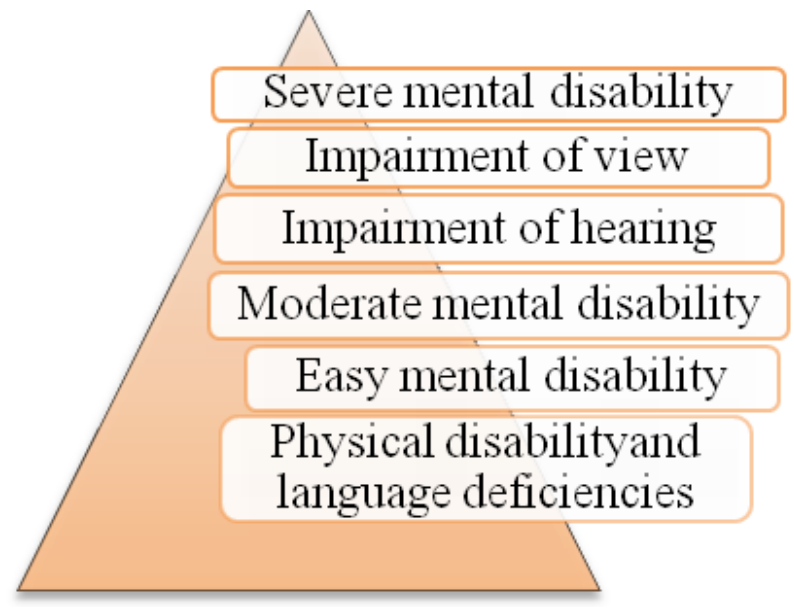

Figure no. 9. Ranking of disabilities

\section{Conclusions and discussions}

The purpose of this study was to investigate the attitude of a small group of parents towards the integration of students with special educational needs in mass education through the group interview method.

Most parents agreed that people with special educational needs have the right to education, considering that the place of the students with special educational needs is with the other children. Although they do not agree with the compulsory integration into the special education, the gravity of the disability influences the attitude. The parents interviewed said that the students with severe disabilities should be only partially integrated into mainstream schools. In addition, most parents are more tolerant of light disabilities, agreeing that students with mild disabilities can make progress in a class with typical students. Parents also exhibit a high degree of tolerance towards the students with physical disabilities, mild mental disabilities and language disorders, with the most reluctant categories being severe mental disabilities and sensory impairments. As for the presence of the students with special educational needs in the classroom, the parents consider that the students with special educational needs monopolize the teacher's attention, to the detriment of the other students, having a negative impact on their own children. 
The results obtained are supported by other studies in the literature that have shown that parents support the inclusion of the students with special educational needs, but their attitude is influenced by the severity, the type of disability of the students and the degree of proximity to their own children. Based on these results, it is desirable to develop a tool to allow parents to investigate parents' attitudes in a larger number, in a shorter time and respecting the principle of anonymity.

The results of the study can be used at institutional level in the activity of school psychologists in mainstream education in combating discrimination and in forming an inclusive policy through the development of programs aimed at changing the attitudes of the members of the community.

\section{Authors note:}

Lupu Nicoleta is Ph.D. student, University of Bucharest, Faculty of Psychology and Educational Sciences Teacher Support, Special School, Brasov, Romania. Topic of interest: Special Psychopedagogy

\section{References}

Boechenek, H.L. (2008). Approving or Disapproving: Parent Perception of Inclusion of the Elementary Level. Dissertation, Walden University, accessed online ProQuest Central.

Brandon, Dorothy P. (2006). Botswana's family and consumer sciences teachers' attitude towards the inclusion of students with physical disabilities. Journal of Family and Consumer Science Education, 24(1), pp. 37-49.

Cheianu-Andrei, D. (2011). Comparative study on the knowledge, attitudes and practices in the field of educational inclusion of the children with special educational needs at family, school, community level. Chișinau: Sociopolis Center of Investigation and Consulting.

Enăchescu, C. (1973). Elements of projective psychology. Bucharest: Scientific Publishing House.
Hilbert, D.D. (2009). Perceptions of parents of preschool children with and without disabilities regarding inclusion. Dissertation, Norman, Oklahoma, accessed on June 14, 2016, ProQuest Central.

Horga, I. (2009). Education of children with special educational needs in mainstream education, personalization endeavour in the Romanian school. Pedagogical Magazine, 7-9, pp. 143-156.

Lupu, N. (2017). Teachers' opinions towards the integration of students with special needs in mass education. Bulletin of the Transilvania University of Brasov, Series VII: Social Sciences, Law, Vol. 10 (59) No. 1, pp. 29-37.

Malcoci, L., Chistruga-Sinchevici, I. (2015). Including the students with special educational needs in community schools. Sociological study. Chişinău: NGO Alliance, Global Campaign for Education, Swedish Organization for Individual Relief.

Moore, J. (2002). Parental Perceptions of Inclusion. Dissertation, Mount Saint Vicent University, online accessed June 14, 2016, ProQuest Central.

Năstase, L., Cocoradă, E. (2007). Fundamentals of Special Psychopedagogy. Introduction in speech therapy. Sibiu: Psychomedia.

Palmer, D.S., Fuller, K., Arora, T., Nelson, M. (2001). Taking Sides: Parent Views on Inclusion for Their Children with Severe Disabilities. Exceptional Children, 67 (4), pp. 467484.

Pivik, J., McComas, J., Laflamme, M. (2002). Barriers and Facilitators to Inclusive Education, Exceptional Children, 69 (1), pp. 97-107.

Yssel, N., Engelbrecht, P., Oswald, M., Eloff, I., Swart, E. (2007). Views of Inclusion. A Comparative Study of Parents Perception in South Africa and the United States. Remedial and Special Education, 26 (6), p. 356.

*** Inclusion of the children with disabilities in the educational system. Sociological study conducted within the project "Promotion of inclusive education at local level through changing the attitudes towards children with disabilities" implemented by IDIS Viitorul in partnership with UNICEF Moldova, accessed online on 03/01/2018 https://www.unicef.org/moldova/Incluziunea_copiilor_cu _dizabiltati.docx. 


\section{Interview Guide}

\section{APPENDIX A}

Type of interview: focus group

Theme: The integration of the students with special educational needs into mainstream education

Place: Braşov

Date of interview: 25.01 .2018

Interview time: $17: 00$

Interview duration: $30-40 \mathrm{~min}$.

Number of interviewees: 10

Socio-demographic data of respondents: gender / age / background

I am ... and I am making a focus group on "The integration of students with special educational needs into mainstream education". Do you agree to answer some of my questions about this topic? Anything related to the theme can be said. There are no restrictions. All experiences are just as valuable for the purpose of the research. There are no better or more interesting experiences. No one judges the other. It is important for everyone to feel free to speak in his/her own way. When someone wants to intervene, they can do it when they feel the need, without asking for permission, but after making sure that the one who was talking before finished what s/he has to say. In order not to lose your idea, you can make a discreet sign to the moderator. We assure you of the confidentiality of the answers. The data will only be used for research purposes. I estimate the interview will take place over 30-40 minutes and I thank you in advance for your participation. Are you ready? Can we start? Does anyone have a question before we start?

\section{Opening questions:}

1. Tell me who you are and what you do?

In order to avoid any doubts, I would like to clarify what a student with special educational needs means and what is involved in the process of his/her integration into mainstream education. The students with Special Educational Needs (CES) are students with sensory impairments (hearing, vision impairment), physical-motor disabilities, mental disabilities (mild / moderate / severe) students with language disorders, students with behavioral disorders, multiple associated disabilities, students with autism, ADHD, other developmental disorders. School integration involves including the students with special educational needs in the mainstream school and the participation, depending on the potential, alongside other children in learning activities.

2. Are you the parents of students with special needs?

3. Are your children colleagues with students with special needs?

Key Questions

4. Are the people with special educational needs entitled to health and recovery services?

5 . Do the people with special needs have the right to education?

6. Are the people with special needs entitled to professional training for employment?

So far, we have talked about your general opinion about the rights of the people with disabilities. Next, we will talk about the integration of the students with disabilities in the mainstream school.

7. What do you think about the statement "The place of the students with special educational needs is in the special education system"?

8. Do you think that the image of school is affected by the presence of the students with special educational needs?

9. What do you think of the statement "School should choose the students with special educational needs depending on the severity of their disability"?

10. What do you think about the statement: "School should not be equipped for the needs of the students with disabilities because it is not a special school"?

11. The presence of the students with special educational needs hinders the classroom activity of other students. What do you think about this statement?

Before I move on, I would like to tell you that I am pleased with the way the discussion progresses. We have learned a lot of interesting things that will help us to better understand the attitude towards integration. Please let me know if you want to make a change in the way we work. Now I would like to talk about the types of disabilities and to what extent you consider that the students with certain disabilities can integrate into mainstream education.

12. What do you think about integrating students with hearing impairment? 
13. What do you think of integrating visually impaired students?

14. What do you think about integrating the students with physical disabilities?

15. What do you think about integrating the students with mild mental disabilities?

16. What do you think about integrating the students with moderate mental disabilities?

17. What do you think about integrating the students with severe mental disabilities?

18. How do you feel about integrating the students with language deficiencies?

I would like to summarize to make sure I have retained the essentials. Some of you people have said ... others have said ...., and others.... Have I forgotten anything?

Final questions

19. What is the general opinion about what we have discussed today? 